\title{
HACIA EL IUS COMMUNE INTERAMERICANO: LA JURISPRUDENCIA DE LA CORTE IDH EN 2013-2016
}

\author{
Toward an Inter-American ius commune: \\ Inter-American Case Law from 2013 to 2016
}

\author{
SERGIO GARCÍA RAMÍREZ \\ Universidad Nacional Autónoma de México \\ sgriijunam@gmail.com \\ JULIETA MORALES SÁNCHEZ² \\ Universidad Nacional Autónoma de México \\ juliettemora@hotmail.com
}

Cómo citar/Citation

García Ramírez, S. y Morales Sánchez, J. (2016).

Hacia el ius commune interamericano: la jurisprudencia de la Corte IDH en 2013-2016.

Anuario Iberoamericano de Justicia Constitucional, 20, 433-463.

doi: http://dx.doi.org/10.18042/cepc/aijc.20.15

\section{Resumen}

Los autores presentan la evolución de la jurisdicción interamericana sobre derechos humanos en el periodo 2013-2016, considerando el marco general del sistema al que esa jurisdicción pertenece, y la jurisprudencia de la Corte Interamericana emitida en la misma etapa. Esto abarca tanto sentencias sobre casos contenciosos como opiniones consultivas. Ha sido intensa y variada la reflexión de la Corte Interamericana, que por este medio contribuye, conforme a su competencia, a integrar

1 Investigador nacional emérito del Sistema Nacional de Investigadores. Exjuez y expresidente de la Corte Interamericana de Derechos Humanos. Doctor en Derecho, magna cum laude, por la Universidad Nacional Autónoma de México (UNAM).

Directora General del Centro Nacional de Derechos Humanos (CENADEH) de la Comisión Nacional de los Derechos Humanos (CNDH) de México. Profesora de la Facultad de Derecho de la UNAM. Investigadora nacional nivel I del Sistema Nacional de Investigadores del CONACYT. Doctora en Derecho por la UNAM (México, 2012) y Doctora en Derecho Constitucional por la Universidad de Castilla-La Mancha. 
lo que los analistas de la materia denominan el «ius commune» interamericano de los derechos humanos, en plena formación. El panorama que a este respecto se presenta comprende temas de gran relevancia en el ámbito interamericano, como el control de convencionalidad, las cuestiones asociadas a los procesos migratorios y al desplazamiento interno, el uso de la fuerza, la libertad de expresión, la tutela de los derechos de mujeres, niños y adolescentes y la protección de miembros de comunidades indígenas $y$ afrodescendientes.

\section{Palabras clave}

Derechos humanos; Corte Interamericana de Derechos Humanos; ius commune; control de convencionalidad; protección de la vida; vida privada; migrantes y desplazados; niños; mujeres; indígenas; uso de la fuerza.

\section{Abstract}

The authors present the evolution of Inter-American case law on human rights from 2013 to 2016, taking into account the general framework of the system of this particular jurisdiction and the case law issued by the Inter-American Court during this period. The case law encompasses both rulings on contentious cases and advisory opinions. Inter-American Court deliberations have been intense and manifold, and as such have contributed, within its area of expertise, to the integration of what analysts in the field call the rapidly growing Inter-American «ius commune» of human rights. The overview given herein covers important topics in the Inter-American sphere, such as conventionality control, issues regarding migratory processes and internal displacement, the use of force, freedom of expression, the protection of the rights of women, children and adolescents, and the protection of members of indigenous communities and people of African descent.

\section{Keywords}

Human Rights; Inter-American Court of Human Rights; ius commune; conventionality control; protection of human life; private life; migrants and displaced persons; children; women; indigenous peoples; use of force. 


\section{SUMARIO}

I. PRESENTACIÓN. II. PANORAMA. III. INFORMES DE LOS ÓRGANOS DE SUPERVISIÓN INTERNACIONAL. IV. JURISPRUDENCIA: 1. Control de convencionalidad; 2. Agotamiento de recursos internos; 3. Protección de la vida; 4 . Vida privada; 5. Violencia contra la mujer; 6 . Derechos de los niños, las niñas y los adolescentes: 6.1. Providencias positivas; 6.2. Migrantes; 6.3. Sistema «penal» juvenil; 6.4. Niñas y niños frente al conflicto armado; 7 . Derechos económicos, sociales, culturales y ambientales; 8. Propiedad de los pueblos indígenas y tribales; 9. Libertad de expresión; 10. Garantías judiciales; 11. Derechos políticos; 12. Expulsión colectiva de migrantes; 13. Refugiados; 14. Extradición, devolución y pena de muerte; 15. Circulación, residencia y desplazamiento; 16. Uso de la fuerza; 17. Derecho de los derechos humanos y derecho internacional humanitario. V. BIBLIOGRAFÍA.

\section{PRESENTACIÓN}

En anteriores números de este Anuario hemos dado cuenta de la jurisprudencia emitida por la Corte Interamericana de Derechos Humanos (Corte IDH, Corte Interamericana o Tribunal Interamericano) —instalada en 1979—, que ha contribuido significativamente al establecimiento del corpus juris de los derechos humanos en el continente americano, particularmente en países de América Latina. La última reseña sobre esta materia apareció en el Anuario Iberoamericano de Justicia Constitucional correspondiente a 2013 (García y Morales, 2013: 441-447 y García, 2014: 67 y ss.) y abarcó las novedades jurisprudenciales que aparecieron entre 2009 y 2012. Ahora ofrecemos un panorama de las afirmaciones y novedades acuñadas por la Corte Interamericana entre el 1 de enero de 2013 y el 31 de marzo de 2016, cuyas expresiones íntegras pueden consultarse en la renovada página web de dicho Tribunal (Corte Interamericana. Recuperado de www.Corte IDH.or.cr/).

\section{PANORAMA}

El sistema interamericano de protección de los derechos humanos ha evolucionado apreciablemente en los últimos años. Hay cambios en la ju- 
risprudencia, como en el horizonte general de los derechos humanos en esta región. En lo que respecta a aquella, se han modificado algunas orientaciones jurisprudenciales, que generaron debate entre los estudiosos y aplicadores de esta materia. Hubo votaciones divididas, soplaron vientos políticos sobre las velas del sistema y este continuó enfrentando los problemas derivados de la estrechez presupuestal. Sin embargo, la jurisdicción interamericana prosiguió su obra constructiva, despachó oportunamente los asuntos de su competencia y aportó novedades dignas de consideración. No padece rezago. Se halla en marcha, a buen paso, como lo muestra el informe presentado en 2015 a la Organización de los Estados Americanos (Corte Interamericana de Derechos Humanos. Informe 2015. Recuperado de http://www.Corte IDH.or.cr/tablas/ informe2015/espanol.pdf).

Se han diversificado los temas abordados por la Corte, que en este sentido asume nuevos retos. Sin embargo, persisten las vulneraciones tradicionales, caracterizadas por hechos de suma violencia: ejecuciones extrajudiciales, torturas, desapariciones forzadas, agravios contra las mujeres, entre otras. Dentro de estos ámbitos, la jurisprudencia se ha ampliado y adquirido mayor profundidad.

Es necesario destacar que la jurisprudencia interamericana debiera influir con mayor fuerza en la legislación, la jurisprudencia y las políticas públicas de los Estados americanos, tanto a escala nacional como en los ámbitos locales y municipales. De ahí la necesidad de que el sistema interamericano tenga mayor cercanía con todos los órdenes de gobierno y exponga sus objetivos y orientaciones de manera asequible a la población, fortaleciendo así el conocimiento y la exigibilidad de los derechos y la observancia del corpus juris por parte de las diversas autoridades de la región. Todo ello permitirá acelerar el tránsito de la reflexión a la acción: de la teoría a la realidad.

Los grandes temas concernientes a los derechos humanos fueron materia de reflexión y deliberación en varios países, desde hace décadas. Argentina y Colombia son ejemplos relevantes. La reforma constitucional latinoamericana del último tercio de siglo milita en esta dirección. En otros países las novedades ingresaron tiempo después, como ocurrió en México, sobre todo a partir de la gran reforma constitucional de 2011 (García y Morales, 2015). Y en algunos medios se mantiene abierto el debate sobre el bloque de constitucionalidad (Astudillo, 2014: 87 y ss.) —que abarca los derechos humanos de fuente internacional-, la interpretación conforme y el principio pro persona, temas superados en otras latitudes. La evolución no ha sido, pues, invariablemente recta y ascendente; ha debido enfrentar y resolver paradojas, obstáculos de diversa naturaleza, retrocesos, amenazas. Y ha tenido que empeñarse, con fuerza, en la tarea de construcción y reconstrucción que caracteriza la consolidación y el avance de los derechos humanos. 
No se ha conseguido la adopción completa y generalizada de la normativa interamericana en los países de la región. De los 35 Estados que conforman la Organización de Estados Americanos, solo 24 son partes en la Convención Americana sobre Derechos Humanos (CADH o Convención Americana), y 20 reconocen la competencia contenciosa de la Corte Interamericana. Es desigual la participación en los protocolos a la Convención y en las convenciones especializadas (Organización de los Estados Americanos. Tratados Multilaterales Interamericanos. Disponible en: http:/www.oas.org/es/sla/ddi/tratados_multilaterales_interamericanos_texto_materias) ${ }^{3}$.

Por lo que toca a la normativa de los derechos humanos, se ha procurado extender el corpus juris de la materia a través de nuevas convenciones en torno a discriminación — textos firmados en Antigua, Guatemala - y personas mayores — suscrito en Washington-; estos instrumentos, preparados en los últimos años se hallan en proceso de ratificación o adhesión. Vale mencionar que los tres incorporan explícitamente la competencia contenciosa de la Corte Interamericana para el conocimiento de litigios en los que se alegue la violación de los derechos reconocidos en ellos (Convención Interamericana contra toda Forma de Discriminación e Intolerancia, 2013; Convención Interamericana contra el Racismo y la Discriminación Racial, 2013; Convención Interamericana sobre Protección de los Derechos Humanos de las Personas Mayores, 2015) ${ }^{4}$.

Hace una década, la Corte inició la celebración de audiencias sobre cumplimiento de resoluciones, práctica positiva que ha ofrecido buenos resultados. En 2015 avanzó en la realización de estas audiencias de supervisión en el territorio de los Estados y emprendió visitas in situ. (Corte IDH, 2015) ${ }^{5}$. También es relevante indicar que durante estos años se consolidó la costumbre de llevar a cabo periodos de sesiones fuera de Costa Rica, sede de la Corte, en

3 Sobre el estado que guardan los tratados interamericanos de derechos humanos, en lo que respecta a suscripción, ratificación o adhesión, véase el link que se indica en la cita.

4 Nos referimos a los siguientes instrumentos, ninguno vigente en los primeros meses de 2016.

5 En el Informe 2015 de la Corte Interamericana de Derechos Humanos da cuenta de las audiencias de supervisión de cumplimiento de sentencias por parte de Honduras (28 de agosto de 2015), con respecto a los casos Juan Humberto Sánchez, López Álvarez, Servellón García y otros, Kawas Fernández, Pacheco Teruel y otros, y Luna López; y Panamá (15 de octubre de 2015), acerca del caso Pueblos Indígenas Kuna de Madungandí y Emberá de Bayano y sus Miembros. Asimismo, la Corte realizó por primera vez una visita in situ en territorio panameño en el marco de la tramitación del proceso de supervisión de cumplimiento del caso mencionado. 
un elevado número de países americanos, tarea iniciada exitosamente en 2005 (García, 2015: 191 y ss.).

En este artículo invocamos principalmente la jurisprudencia de la Corte Interamericana en el período sujeto a examen. Es indispensable añadir, no obstante, que las obras en torno al sistema interamericano de protección de los derechos humanos, y específicamente sobre el Tribunal de esta competencia y región, son cada vez más numerosas, consultadas y apreciadas. Versan sobre el sistema o la Corte en su conjunto o acerca de múltiples cuestiones específicas (González, 2013; Gozaíni, 2016) ${ }^{6}$. También se han multiplicado las obras que examinan la aplicación de la jurisprudencia interamericana en los países de la región (por ejemplo, México. Así, García y Del Toro, 2015; Corzo Sosa, E. et. al, 2013; Peláez, 2014) y los estudios en torno al denominado «diálogo entre sistemas», que informan acerca de los puntos más relevantes de conexión o distancia entre el sistema europeo - cuyas resoluciones han tenido amplia recepción en la jurisprudencia de la Corte IDH - y el sistema interamericano (Santolaya, 2015) ${ }^{7}$.

\section{INFORMES DE LOS ÓRGANOS DE SUPERVISIÓN INTERNACIONAL}

Los informes temáticos de la Comisión Interamericana de Derechos Humanos (CIDH) han sido numerosos en 2014 y 2015 (Comisión Interamericana de Derechos Humanos. Informes Temáticos. Recuperado de http://www. oas.org/es/cidh/informes/tematicos.asp). En 2016 aquella emitió informes sobre la situación de los derechos humanos en diversos Estados: Guatemala, México, Honduras y República Dominicana (Corte Interamericana de Derechos Humanos. Informes. Disponible en: http://www.oas.org/es/cidh/informes/pais.asp). Por su parte, la Corte IDH dio cuenta de diversas cuestiones importantes en su Informe Anual 2015 (Corte IDH, 2015) ${ }^{8}$.

6 En artículos anteriores publicados en este Anuario hemos citado la bibliografía más accesible y consultada — sin perjuicio de omisiones involuntarias, que lamentamos-; ahora mencionaremos sólo dos obras adicionales, de fechas recientes, elaboradas por tratadistas muy estimables, que se suman al examen de la materia que nos interesa.

7 En este orden de reflexiones cabe mencionar como obra muy ilustrativa, la que se indica en la referencia inserta al párrafo.

8 Además de la información general acostumbrada, este documento se refiere a sesiones celebradas, función contenciosa, supervisión de cumplimiento, medidas provisionales, función consultiva, desarrollo jurisprudencial (a través de rubros sobre temas específicos) presupuesto, 


\section{JURISPRUDENCIA}

La jurisprudencia interamericana en sentido estricto, esto es, los criterios establecidos por la Corte IDH como intérprete de la Convención Americana y de otros tratados de la región, que han sido acogidos por varios Estados, ha influido crecientemente en los ordenamientos internos. Esa jurisprudencia posee carácter vinculante inter partes, obviamente, en lo que toca a la solución específica de una controversia, pero también erga omnes en lo que atañe a la interpretación de la norma invocada o aplicada, con respecto a los Estados parte en un litigio y a todos los restantes que se hallan bajo el imperio del mismo orden convencional. La admisión de este último efecto, verdaderamente relevante, ha sido afirmada por el propio Tribunal incluso en lo que concierne a sus opiniones consultivas, cuyo carácter vinculante no fue sostenido en anteriores pronunciamientos. Esta afirmación deriva de las observaciones de la Corte a propósito del control de convencionalidad (Corte IDH, 2014).

A continuación se ofrece una apretada síntesis de los temas abarcados por la jurisprudencia de la Corte Interamericana en el período al que se refiere esta revisión. Dada la naturaleza de la presente reseña solo mencionaremos algunos puntos sobresalientes.

\section{CONTROL DE CONVENCIONALIDAD}

En el período del que damos cuenta continuó el desarrollo y la aplicación de una doctrina generada años atrás por la misma Corte Interamericana: el control de convencionalidad (Vergottini, 2010: p. 112; Cantor, 2008: 46 y 167-171; Hitters, 2009: 1-5; Von Bogdandy et al., 2010: 449; Ferrer Mac-Gregor Poisot, 2012: 422; Sagüés, 2013: 344-346; Brewer-Carías et. al., 2013: 47; Ferrer Mac-Gregor, 2013: 132-133; Ayala Corao, 2012: 133 y ss., 142, n. 502

Fondo de Asistencia Legal a Víctimas y Defensor Interamericano, difusión de jurisprudencia, varias actividades, diálogo con otros tribunales y organismos, convenios y relaciones con diversos órganos. Es interesante mencionar que el promedio de duración del procesamiento de casos fue de 22’2 meses, lo que significa la mitad del tiempo que se requería en 1996.

9 La Corte consideró «necesario que los diversos órganos del Estado realicen el correspondiente control de convencionalidad, también sobre la base de lo que señale en ejercicio de su competencia no contenciosa o consultiva, la que indudablemente comparte con su competencia contenciosa el propósito del sistema interamericano de derechos humanos, cual es 'la protección de los derechos fundamentales de los seres humanos'. 
y 147 n. 509; Caballero Ochoa, 2013: 75-76, etc. $)^{10}$, que abarca tanto la jurisprudencia supranacional como la jurisprudencia interna. En este orden existe un evidente progreso, generalmente reconocido por los estudiosos del tema. No obstante, persisten las resistencias, radicadas en ciertos sectores de la magistratura y alimentadas por el desconocimiento de los operadores legislativos y administrativos sobre el alcance de la protección de los derechos fundamentales. Esto retrae, en alguna medida, la adopción eficaz de medidas de carácter estructural que eviten la reiteración de ciertas violaciones. En este mismo sentido operan negativamente la impunidad, la corrupción y la pobreza.

La Corte IDH ha reiterado que el control debe ser ejercido por todos los órganos del Estado (Corte IDH, 2014a; 2014b) ${ }^{11}$, no solo por los jueces u órganos vinculados con la Administración de Justicia, como se sostuvo anteriormente. No se puede ignorar que este parecer cuenta con el favor de muchos analistas, pero también se ha considerado que el ámbito judicial es el más apropiado para la operación del control, como se sostuvo en la primera etapa de la formación de esta doctrina.

\section{AGOTAMIENTO DE RECURSOS INTERNOS}

En el caso de Allan Brewer Carias vs. Venezuela difirieron las posiciones adoptadas por la Comisión Interamericana y la Corte IDH (Corte IDH, 2014c) con respecto a las excepciones al requisito de previo agotamiento de los recursos internos previsto en el art. 46.2 de la CADH. Cabe observar que el Tribunal Europeo de Derechos Humanos parece haber avanzado con mayor amplitud en el ejercicio de las excepciones al mencionado requisito (Corte IDH, 2012).

La Corte Interamericana entiende que para los fines del previo agotamiento de recursos internos debe atenderse al concepto de plazo razonable, no a la exigencia de un plazo uniforme de seis meses (Corte IDH, 2013). El Tribunal Interamericano afirmó nuevamente, asimismo, que los argumentos esgrimidos por los Estados ante la Comisión durante la etapa de admisibilidad del caso deben guardar correspondencia con los expuestos, en su hora, ante la Corte.

10 Es muy nutrida y creciente la bibliografía sobre esta materia, que ha adquirido importancia extraordinaria en el Derecho interamericano de los derechos humanos, como se puede apreciar en la cita.

11 Se relaciona con la investigación y el proceso penal en contra de un exministro de Finanzas y exministro de Recursos Naturales de Surinam, sentenciado por falsificación el 5 de noviembre de 2003. La Corte decidió que el Estado era responsable por la violación del derecho a recurrir el fallo y por la restricción de circulación que se impuso a la víctima. 


\section{PROTECCIÓN DE LA VIDA}

En el examen de esta cuestión, que ha sido analizada por la Corte en diversos casos, que alcanzan a definir una jurisprudencia clara y constante, el Tribunal reiteró que para establecer la existencia de violación al derecho a la vida no se requiere acreditar la culpabilidad o intencionalidad de los autores, ni identificar individualmente a los agentes del hecho ilícito. Basta con «demostrar que se han verificado acciones u omisiones que hayan permitido la perpetración de esas violaciones o que exista una obligación del Estado que haya sido incumplida» (Corte IDH, 2013a; 2013b). En suma, se insiste en el carácter objetivo de la responsabilidad a cargo del Estado.

\section{VIDA PRIVADA}

El examen acerca del derecho a la vida privada llevó al Tribunal a pronunciarse sobre la identidad personal. Aquella y esta se hallan sustentadas "en una experiencia histórica y biológica», así como en la forma en que el individuo se relaciona con otras personas en el medio familiar y social. «La identidad es un derecho que comprende varios elementos, entre ellos [...] la nacionalidad, el nombre y las relaciones familiares». La CADH protege estos datos en sí mismos. No siempre viene a cuentas, como conjunto, en todos los casos vinculados con el derecho a la identidad (Corte IDH, 2014d $)^{12}$. En el ámbito de protección de la vida privada figura la vida sexual (Corte IDH, $2014 \mathrm{e})^{13}$.

12 Caso Rochac Hernández y otros. Fondo, reparaciones y costas, Sentencia de 14 de octubre de 2014, Serie C 285, párr. 116. Se refiere a la desaparición forzada de cinco niños en la circunstancia del conflicto armado en el que hubo operativos militares de "contrainsurgencia»; igualmente, falta de investigación seria, diligente y en plazo razonable. Se condenó al Estado por violación de los derechos a la libertad e integridad personal, ida, reconocimiento de la personalidad jurídica, vida familiar y garantías y protección judiciales.

13 Caso Rodríguez Vera y otros (Desaparecidos del Palacio de Justicia). Excepciones preliminares, fondo, reparaciones y costas. Sentencia de 14 de noviembre de 2014. Serie C 287, párr. 425. El litigio concierne a la toma y retoma violenta del Palacio de Justicia en Bogotá, los días 6 y 7 de noviembre de 1985 . Hubo desaparición forzada de las presuntas víctimas durante el operativo de la retoma; desaparición y posterior ejecución de un magistrado y detención y tortura de cuatro personas más; se alegó la falta de esclarecimiento de los hechos y de sanción de los responsable. La Corte IDH condenó por desaparición forzada, asociada a la violación de derechos en materia de libertad 
La Corte Interamericana en este periodo, con base en el caso Atala Riffo y niñas, dispuso que «está proscrita por la Convención cualquier norma, acto o práctica discriminatoria basada en la orientación sexual de la persona. En consecuencia, ninguna norma, decisión o práctica de derecho interno, sea por parte de autoridades estatales o por particulares, pueden disminuir o restringir, de modo alguno, los derechos de una persona a partir de su orientación sexual» (Corte IDH, 2016) ${ }^{14}$. Así, la existencia de una normatividad interna que no permita el pago de pensiones a parejas del mismo sexo, es una diferencia de trato que vulnera el derecho a la igualdad y no discriminación (Corte IDH, 2014).

Dentro del mismo espacio de consideraciones atinentes a la vida privada, la jurisprudencia interamericana señala que el Estado se halla obligado a «garantizar el derecho a la honra y la reputación mediante acciones positivas». Esto puede implicar, en ciertos casos, la adopción de medidas dirigidas a asegurar ese derecho frente a la interferencia de las autoridades públicas y de las «personas o instituciones privadas, incluyendo los medios de comunicación» (Corte IDH, 2013c) $)^{15}$.

\section{VIOLENCIA CONTRA LA MUJER}

La Corte IDH se ha referido a las obligaciones que asumen los Estados conforme al art. 7 de la Convención de Belém do Pará. Estos deberes especifican y complementan los previstos en los arts. 4 y 5 de la Convención Americana. Al respecto, el Tribunal Interamericano sostiene que «los Estados deben adoptar medidas integrales para cumplir con la debida diligencia en casos de violencia contra las mujeres».

personal, integridad personal, vida y reconocimiento de la personalidad jurídica, entre otros conceptos.

14 Caso Duque. Excepciones Preliminares, fondo, reparaciones y costas. sentencia de 26 de febrero de 2016. Serie C 310, párrs. 104-106. El caso trata sobre la exclusión de una persona de la posibilidad de obtener una "pensión de sobrevivencia» tras la muerte de su pareja, ya que se trataba de una pareja del mismo sexo. La víctima sufrió discriminación con base en su orientación sexual y por ser portador de VIH.

15 Caso Mémoli. Excepciones preliminares, fondo, reparaciones y costas. Sentencia de 22 de agosto de 2013. Serie C 265, párr. 125. Se violó la libertad de expresión de dos personas a causa de la condena penal que se impuso a las víctimas debido a sus denuncias públicas sobre la venta supuestamente irregular de nichos en el cementerio local; asimismo, hubo violaciones procesales. La decisión de la Corte se tomó por mayoría de votos. 
Por ello, «deben contar con un adecuado marco jurídico de protección, con una aplicación efectiva del mismo y con políticas de prevención y prácticas que permitan actuar de una manera eficaz ante las denuncias». La estrategia de prevención de violaciones «debe ser integral, es decir, debe prevenir los factores de riesgo y a la vez fortalecer las instituciones para que puedan proporcionar una respuesta efectiva a los casos de violencia contra la mujer» (Corte IDH, 2015a $)^{16}$.

En torno a la desaparición de mujeres, la jurisprudencia sostiene la existencia de «un deber de debida diligencia estricta [...] respecto a su búsqueda durante las primeras horas y los primeros días». Se trata de una obligación de medios, rigurosa, que exige «la realización exhaustiva de actividades de búsqueda». En el mismo orden de consideraciones, se dispone la existencia de "procedimientos adecuados para las denuncias y que éstas conlleven una investigación efectiva desde las primeras horas. Las autoridades deben presumir que la persona desaparecida sigue con vida hasta que se ponga fin a la incertidumbre sobre la suerte que ha corrido» (Corte IDH, 2015a ${ }^{17}$. La Corte ha fijado el parámetro de investigación que debe atenderse en supuestos de investigación de violencia sexual (Corte, 2015a) ${ }^{18}$.

Al aplicar la perspectiva de género al examen de hechos violatorios, cometidos en un entorno de cultura patriarcal, el Tribunal señaló que «las pruebas relativas a los antecedentes sexuales de la víctima son en principio inadmisibles, por lo que la apertura de líneas de investigación sobre el comportamiento social o sexual previo de las víctimas en casos de violencia de género no es más que la manifestación de políticas o actitudes basadas en estereotipos de género" (Corte IDH, 2014f) ${ }^{19}$.

16 Caso Velásquez Paiz y otros. Este caso corresponde a la falta de diligencia del Estado con respecto a la desaparición de la presunta víctima, en el contexto de violencia contra las mujeres, que incluyó el asesinato de la víctima con extrema violencia, incluso sexual. Igualmente, irregularidades durante la investigación de los hechos. La Corte resolvió que el Estado era responsable por la violación a la garantía de libre y pleno ejercicio de los derechos a la vida e integridad personal en relación con los arts. 1.1 y 2 de la Convención Americana y 7 de la Convención de Belem do Para; así como a las garantías judiciales y a la protección judicial de algunos familiares de la víctima.

17 Caso Velásquez Paiz y otros, párr. 122.

18 La Corte estableció los estándares para la investigación penal de la violencia sexual; destacó la importancia que reviste la primera etapa de la investigación, y ponderó la necesidad de practicar inspecciones sobre el cuerpo de la víctima y preservar diversos datos de prueba.

19 Caso Veliz Franco y otros. Excepciones preliminares, fondo, reparaciones y costas. Sentencia de 19 de mayo de 2014. Serie C 277, párr. 209. Este caso se motivó por la falta 
La Corte IDH considera que las declaraciones de las víctimas de violencia sexual constituyen un elemento fundamental para el esclarecimiento de los hechos; las inconsistencias que puedan existir en tales declaraciones no determinan que se deseche la posible comisión del ilícito sujeto a investigación (Corte IDH, 2014g) ${ }^{20}$.

En torno a estas cuestiones, conviene recordar que la Corte IDH ya ha establecido que la violencia sexual constituye una forma de tortura (Corte IDH, 2006) (Corte IDH, 2010).

En sus pronunciamientos, el Tribunal Interamericano ha examinado el ejercicio de la violencia contra las mujeres en contextos de conflicto interno y los efectos generados en estas situaciones (Corte IDH, 2014g). Asimismo, ha sostenido diversos criterios importantes para el examen integral de una materia de suyo compleja y relevante. Mencionemos algunos: la ineficacia judicial frente a casos individuales de violencia contra la mujer propicia impunidad y constituye una forma de discriminación (Corte IDH, 2015a); es preciso evitar la «invisibilización de las circunstancias previas a la muerte» cuando hay indicios que permiten suponer la existencia de actos violentos anteriores al fa-

de respuesta eficaz del Estado a la denuncia presentada por una persona por la desaparición de su hija de 15 años. Aunado a ello existieron una serie de irregularidades durante la investigación de dicha desaparición y posterior muerte de la niña, entre ellas la falta de realización de diligencias al momento de reportar la desaparición y fallas en la preservación de la escena del crimen. El Tribunal interamericano decidió que el Estado violó su deber de garantizar el libre y pleno ejercicio de los derechos a la vida y a la integridad personal en relación con los derechos del niño, así como algunas de las obligaciones contenidas en la Convención Interamericana para Prevenir, Sancionar y Erradicar la Violencia contra la Mujer.

El caso concierne a la detención ilegal y arbitraria de una mujer, su violación y tortura a manos de agentes de la policía. En supuestos de agresión sexual —señaló la Corte IDH-, «la declaración de la víctima constituye una prueba fundamental sobre el hecho", considerando las circunstancias en las que éste se realiza; "las imprecisiones en declaraciones relacionadas a violencia sexual o la mención de algunos de los hechos alegados solamente en algunas de estas no significa que sean falsas o que los hechos relatados carezcan de veracidad». Caso Espinoza Gonzáles. Excepciones preliminares, fondo, reparaciones y costas. Sentencia de 20 de noviembre de 2014. Serie C 289, párr. 150. Se condenó al Estado por violación de los derechos a la libertad personal, integridad personal, protección a la honra y dignidad, garantías y protección judiciales y deber de no discriminación, así como por violación de las obligaciones previstas en la Convención Interamericana para Prevenir y Sancionar la Tortura y en la Convención Interamericana para Prevenir, Sancionar y Erradicar la Violencia contra la Mujer. 
llecimiento (Corte IDH, 2015a), con especial énfasis cuando la víctima es una niña (Corte IDH, 2014f); la violación sexual no se acredita necesariamente a través de enfermedades o lesiones corporales: es preciso considerar que las víctimas también experimentan «severos daños y secuelas psicológicas y aun sociales» (Corte IDH, 2014g).

\section{DERECHOS DE LOS NIÑOS, LAS NIÑAS Y LOS ADOLESCENTES}

Durante el periodo que se reseña, la Corte Interamericana emitió algunas sentencias concernientes a los derechos de las niñas y los niños. En ellas se trazan o afirman ejes jurisprudenciales relevantes para la elaboración de políticas públicas.

\subsection{Providencias positivas}

Veamos algunas cuestiones destacadas en este ámbito, dominado por el principio de interés superior del infante y de responsabilidad estatal, social y familiar. En torno a este punto, de muy amplio alcance, y al amparo de la Convención sobre los Derechos del Niño, integrante del corpus iuris de los derechos de la niñez, la Corte IDH advierte que «el Estado no solo debe abstenerse de interferir indebidamente en las relaciones privadas o familiares de la niña y del niño, sino también [...] debe adoptar (según las circunstancias) providencias positivas para asegurar el ejercicio y disfrute pleno de sus derechos. Esto exige que el Estado, como responsable del bien común, resguarde el rol preponderante de la familia en la protección del niño; y preste asistencia del poder público a la familia, mediante la adopción de medidas que promuevan la unidad familiar (Corte IDH, 2014d).

La Corte IDH ha sido enfática en que «la adopción de medidas especiales para la protección del niño corresponde tanto al Estado como a la familia, la comunidad y la sociedad a la que aquel pertenece» (Corte IDH, 2013d $)^{21}$.

21 Caso Mendoza y otros. Excepciones preliminares, fondo y reparaciones. Sentencia de 14 de mayo de 2013 Serie C 260, párr. 141. Sentencia a privación perpetua de la libertad por hechos cometidos cuando los sentenciados eran menores de edad. El caso se plantea en aplicación de un sistema de justicia de adolescentes que permitía que estos fueran tratados igual que los adultos infractores. Igualmente, restricciones al alcance de recursos interpuestos y condiciones de detención incompatibles con la dignidad humana; muerte de uno de los detenidos y tortura, que no fueron investigados efectivamente. Se condenó por violación de los derechos del niño, entre otros conceptos, algunos concernientes a la Convención Interamericana para Prevenir y Sancionar la Tortura. 
Por ello, «toda decisión estatal, social o familiar que involucre alguna limitación al ejercicio de cualquier derecho de un niño o una niña, debe tomar en cuenta el principio del interés superior del niño y ajustarse rigurosamente a las disposiciones que rigen esta materia» (Corte IDH, 2013d).

\subsection{Migrantes}

En el ejercicio de su función consultiva - que ha sido una fuente relevante del derecho interamericano de los derechos humanos-, la Corte se ha referido a diversas cuestiones que atañen a los niños migrantes, entre las que figuran la protección internacional y la puntual y detallada observancia de principios y reglas del debido proceso (Corte IDH, 2014) cuando se indagan y resuelven hechos relacionados con el quebrantamiento de normas migratorias y la desprotección de menores de edad que viajan sin la compañía de familiares u otros allegados. En el marco de la opinión consultiva, posee especial relevancia la adopción de medidas que afectan la libertad de los menores de edad (Corte IDH, 2014).

En esta oportunidad, la Corte también se pronunció sobre la ruptura de la unidad familiar producida por la expulsión «de uno o ambos progenitores por infracciones migratorias relacionadas con (su) ingreso o permanencia». Consideró que ciertas medidas adoptadas por autoridades migratorias son claramente desproporcionadas, «pues el sacrificio inherente a la restricción del derecho a la vida familiar que puede traer aparejado repercusiones en la vida y el desarrollo de la niña o del niño aparece como irrazonable o desmedido frente a las ventajas que se obtienen al forzar al progenitor a abandonar el territorio por causa de una infracción de carácter administrativo» (Corte IDH, 2014).

En las sentencias del Tribunal —que se hallan, por supuesto, en la misma línea de ideas que la opinión consultiva a la que antes nos referimos - destaca asimismo la prioridad invariablemente asignada al interés superior de niñas y niños. Las decisiones de las autoridades que resuelvan la separación familiar por la condición migratoria de alguno de los progenitores «debe contemplar las circunstancias particulares del caso concreto, garantizando así una decisión individual», atenta al fin legítimo que se propone alcanzar la Convención aplicable, y ser «idónea, necesaria y proporcionada» (Corte IDH, 2014b)22

22 Detención arbitraria y expulsión sumaria de personas, inclusive niños, además de impedimento para obtener nacionalidad. Hubo violación del derecho al reconocimiento de la personalidad jurídica, nacionalidad, nombre, identidad, no discriminación, libertad y derechos del niño. 
Entre los datos que es preciso considerar en esta materia, casuísticamente, se hallan: a) historia inmigratoria, lapso temporal de la estadía y la extensión de los lazos del progenitor y/o de su familia con el país receptor; b) consideración sobre la nacionalidad, guarda y residencia de los hijos de la persona que se pretende deportar; c) alcance de la afectación que genera la ruptura familiar debido a la expulsión, incluyendo las personas con quiénes viven la niña o el niño, así como el tiempo que estos han permanecido en la unidad familiar, y d) alcance de la perturbación en la vida diaria de la niña o del niño si cambiara su situación familiar debido a la expulsión de la persona que los tiene a su cargo (Corte IDH, 2014b).

La detención administrativa es el último recurso y debe aplicarse conforme al principio de proporcionalidad; es preciso optar por medidas menos lesivas, tomando en cuenta que las previsiones legales y judiciales revisten mayor gravedad cuando se trata de niñas y niños (Corte IDH, 2014b)23.

La separación de los menores con respecto a sus padres se analiza en el mismo marco de la expulsión. La Corte Interamericana consideró que las separaciones dipuestas por agentes del Estado, que impiden la reunificación familiar de los niños, generan «afectaciones específicas en cada uno de los integrantes de las familias, así como en las dinámicas propias de cada una de estas» (Corte IDH, 2014d).

\subsection{Sistema «penal» juvenil}

Si el «interés superior del niño como principio interpretativo (está) dirigido a garantizar la máxima satisfacción de los derechos del niño, en contrapartida, también debe servir para asegurar la mínima restricción de tales derechos». En tal virtud, los principios del «interés superior del niño, de autonomía progresiva y de participación tienen una relevancia particular en el diseño y operación de un sistema de responsabilidad penal juvenil» (Corte IDH, 2013d). La Corte sostiene, en el mismo ámbito de reflexiones, el respeto al principio de trato diferenciado con respecto a quienes cometen un delito, según su edad (Corte IDH, 2013d) ${ }^{24}$.

23 Los Estados -señaló la Corte IDH - deben utilizar medidas menos lesivas que la privación de libertad cuando se trata de niños no acompañados o separados de sus padres, en el supuesto de un procedimiento migratorio.

24 «Si bien los niños cuentan con los mismos derechos humanos que los adultos durante los procesos, la forma en que ejercen tales derechos varía en función de su nivel de desarrollo. Por lo tanto, es indispensable reconocer y respetar las diferencias de trato que corresponden a diferencias de situación, entre quienes participan en un proceso. Lo anterior corresponde al principio de trato diferenciado que, aplicado en el ámbito 
Por ello, cuando no sea posible evitar la intervención judicial en supuestos de comisión de conductas calificadas por la ley penal como delictivas, los menores de 18 años «deberán quedar sujetos, para los fines del conocimiento respectivo y la adopción de las medidas pertinentes, solo a órganos jurisdiccionales específicos distintos de los correspondientes a los mayores de edad» (Corte IDH, 2013d). A la hora de elegir la medida aplicable a estos sujetos, «opera de manera relevante el principio de proporcionalidad. Conforme a este principio debe existir un equilibrio entre la reacción penal y sus presupuestos, tanto en la individualización de la pena como en su aplicación judicial» (Corte IDH, 2013d). Los Estados deben establecer en su legislación programas de libertad anticipada cuando la situación de los niños ha cambiado (Corte IDH, 2013d). Es inaceptable la privación perpetua de libertad de menores de edad (Corte IDH, 2013d $)^{25}$.

\subsection{Niñas y niños frente al conflicto armado}

En relación con los conflictos armados que se han presentado en varios países del área, la Corte IDH analiza —entre otros temas de suma importancia- las afectaciones derivadas del desplazamiento de personas que se traducen en grave carencia de servicios básicos (Corte IDH, 2013e $)^{26}$. Asimismo,

penal, implica que las diferencias de los niños y los adultos, tanto por lo que respecta a 'su desarrollo físico y psicológico, como por sus necesidades emocionales y educativas', sean tomadas en cuenta para la existencia de un sistema separado de justicia penal juvenil.»

25 «La Convención Americana sobre Derechos Humanos no hace referencia a la prisión o reclusión perpetuas. No obstante, el Tribunal destaca que, de conformidad con el art. 5.6 de la Convención Americana, «[1] as penas privativas de la libertad tendrán como finalidad esencial la reforma y la readaptación social de los condenados». En ese sentido, la Convención sobre los Derechos del Niño prevé que, cuando un niño haya sido declarado culpable por la comisión de un delito, tiene derecho a «ser tratado de manera acorde con el fomento de su sentido de la dignidad y el valor, que fortalezca el respeto del niño por los derechos humanos y las libertades fundamentales de terceros y en la que se tengan en cuenta la edad del niño y la importancia de promover la reintegración del niño y de que éste asuma una función constructiva en la sociedad». La privación perpetua de libertad no es proporcional con la finalidad de la sanción penal a niños.

26 Caso de las Comunidades Afrodescendientes Desplazadas de la Cuenca del Río Cacarica (Operación Génesis). Excepciones preliminares, fondo, reparaciones y costas. Sentencia de 20 de noviembre de 2013. Serie C 270, párr. 329. Este caso deriva de una operación realizada en zona cercana a los territorios de comunidades afrodescendientes, 
subraya «la especial vulnerabilidad (de los niños y las niñas), que se hace aún más evidente en una situación de conflicto armado interno (pues aquellos son los sujetos) menos preparados para adaptarse o responder a dicha situación $y$, tristemente, son quienes padecen sus excesos de forma desmesurada». En consecuencia, se les debe proporcionar atención adecuada y proveer medidas oportunas para facilitar la reunión de las familias temporalmente separadas» (Corte IDH, 2013e).

\section{DERECHOS ECONÓMICOS, SOCIALES, CULTURALES Y AMBIENTALES}

La Corte IDH ha recordado "la interdependencia e indivisibilidad existente entre los derechos civiles y políticos y los derechos económicos, sociales y culturales». Unos y otros deben ser «entendidos integralmente como derechos humanos, sin jerarquía entre sí y exigibles en todos los casos ante aquellas autoridades que resulten competentes para ello» (Corte IDH, 2013f).

Algunos analistas consideran cuestionable la existencia de instrumentos separados para derechos civiles y políticos, por una parte, y derechos económicos, sociales y culturales, por la otra, como ocurre en los planos universal - a través de los Pactos de Naciones Unidas-y americano - por medio de la CADH y el Protocolo de San Salvador. Asimismo, se ha objetado la alusión a generaciones de derechos. Tómese en cuenta, sin embargo, que esta solo se relaciona con la aparición sucesiva de las llamadas generaciones o familias de derechos en el escenario histórico, tanto constitucional como internacional (en este caso, el escenario europeo y americano).

Hay pasos adelante, todavía insuficientes, en la exigibilidad de los derechos económicos, sociales, culturales y ambientales (DESCA). Persiste el déficit de asistencia jurídica gratuita e instrumentos de apoyo realmente accesibles que contribuyan al verdadero ejercicio de los derechos, a través de mecanismos jurisdiccionales (justiciabilidad) (Langford, 2013) ${ }^{27}$ y no jurisdiccionales. Hay un largo camino por recorrer en el tránsito que conduce de la concepción de los DESCA como servicios públicos a su afirmación como derechos humanos exigibles y justiciables.

con violencia sobre las personas y desplazamiento. Hubo falta de protección judicial, violación a la integridad, derecho a la vida, circulación y residencia, incumplimiento de la garantía de asistencia humanitaria.

27 La bibliografía a este respecto es muy abundante y creciente, como en otros extremos del régimen de los derechos humanos. Entre las publicaciones recientes que ofrecen un importante panorama del estado que guarda la justiciabilidad de los derechos humanos en numerosos países, sobre todo dentro del área americana. 
El Tribunal Interamericano se ha ocupado específicamente del derecho a la salud, al que alude el art. 10 del Protocolo de San Salvador. Este derecho no es justiciable en los términos de dicho protocolo, pero el juzgador puede brindar protección a través de los derechos que sí lo son conforme a la $\mathrm{CADH}$. Es así que la Corte IDH recuerda que el art. 4 del Pacto de San José, que garantiza el derecho de la persona a no ser privada de la vida arbitrariamente, igualmente señala el deber de los Estados de adoptar las medidas necesarias para crear un marco normativo adecuado que disuada cualquier amenaza al derecho a la vida. (Corte IDH, 2015b).

El deber de garantía estatuido en el art. 1.1 CADH se proyecta sobre el derecho a la integridad personal, reconocido por el art. 5.1, y este se halla directa e inmediatamente vinculado con la atención a la salud humana. La falta de atención médica adecuada puede conllevar la vulneración del art. 5.1. La protección del derecho a la integridad personal supone la regulación de los servicios de salud en el ámbito interno, así como el establecimiento de diversos mecanismos dispuestos para obtener la efectividad de dicha regulación (Corte IDH, 2015b).

Con respecto a la obligación del Estado relacionada con la atención médica en instituciones privadas, la Corte IDH ha sostenido que «el deber de supervisión y fiscalización es del Estado, aun cuando el servicio de salud lo preste una entidad privada. El Estado mantiene la obligación de proveer servicios públicos y de proteger el bien público respectivo» (Corte IDH, 2015b) ${ }^{28}$.

Cuando una enfermedad representa un riesgo para la vida y las deficiencias en la atención de salud empeoran dicha situación, «el daño que se cause a la salud constituye una afectación del derecho a la vida, dado el peligro de muerte que en diversos momentos ha enfrentado y puede enfrentar la víctima debido a su enfermedad» (Corte IDH, 2015b).

En torno al derecho a la salud integrado en la categoría de los derechos económicos, sociales y culturales, la Corte manifestó: «El Protocolo de San Salvador establece que entre las medidas para garantizar el derecho a la salud,

28 Cuando un paciente está bajo el cuidado directo del Estado o de un hospital privado que tenga convenio o contrato con aquél, debe responder el Estado por las violaciones a derechos que sufra el paciente. La Corte IDH cita al Tribunal Europeo de Derechos Humanos para señalar que el Estado mantiene el deber de otorgar licencias y ejercer supervisión y el control sobre instituciones privadas. El Tribunal Interamericano precisa: «Cuando se trata de competencias esenciales relacionadas con la supervisión y fiscalización de la prestación de servicios de interés público, como la salud, sea por entidades públicas o privadas (como es el caso de un hospital privado), la responsabilidad resulta por la omisión en el cumplimiento del deber de supervisar la prestación del servicio para proteger el bien respectivo». 
los Estados deben impulsar la total inmunización contra las principales enfermedades infecciosas [...], la prevención y el tratamiento de las enfermedades endémicas, profesionales y de otra índole», y «la satisfacción de las necesidades de salud de los grupos de más alto riesgo y que por sus condiciones de pobreza sean más vulnerables» (Corte IDH, 2015b).

En el periodo al que se refiere esta revisión, la Corte ha examinado cuestiones vinculadas con discriminación y VIH/SIDA. Como se sabe, el Tribunal se ha pronunciado en muchas ocasiones acerca de la discriminación, materia que abordan dos proyectos de Convención acerca de la discriminación a los que supra nos referimos-, de muy reciente fecha, que se hallan en proceso de adopción por los Estados americanos. La CADH no contiene una definición o caracterización de la discriminación — cuyo rechazo forma parte del jus cogens_-, pero está claramente establecido que aquella se relaciona con cualquier distinción, exclusión, restricción o preferencia basada en motivos que señala la Convención, entre los que figura "cualquier (...) condición social» que tenga por objeto anular o menoscabar los derechos humanos y libertades fundamentales de las personas (Corte IDH, 2015 b) ${ }^{29}$.

El Tribunal señala que «las personas con VIH han sido históricamente discriminadas debido a las diferentes creencias sociales y culturales que han creado un estigma alrededor de la enfermedad». Es así que esta circunstancia puede generar «barreras sociales y actitudinales» para el acceso del individuo al ejercicio de sus derechos en pie de igualdad con otros sujetos. La relación que existe entre los obstáculos de esta naturaleza y la salud de las personas justifica el empleo del modelo social de la discapacidad como enfoque relevante para valorar el alcance de algunos derechos involucrados (Corte IDH, 2015b).

En esta línea de consideraciones, la Corte IDH afirma que como producto de la evolución del concepto de discapacidad, el modelo social en esta materia entiende aquella como el resultado de la interacción entre las características funcionales de una persona y las barreras en su entor Por ello, la «discapacidad no se define exclusivamente por la presencia de una deficiencia física, mental, intelectual o sensorial, sino que se interrelaciona con las barreras o

29 El Tribunal interamericano consideró prohibida la discriminación por portación de VIH, bajo el concepto de «otra condición social» (art. 1.1 CADH). En este supuesto se presenta también un elemento potencialmente generador de discapacidad cuando existan barreras económicas, sociales o de otra índole derivadas del VIH que afecten el desarrollo y participación social del sujeto. Caso Gonzales Lluy y otros vs. Ecuador, párr. 255. El presente caso derivó de la afectación a la vida digna e integridad personal de una niña contagiada de VIH tras una transfusión de sangre. Se alegó la falta de garantía por parte del Estado en su papel de supervisor de las entidades privadas de atención a la salud, así como deficiencias en el proceso penal. 
limitaciones que socialmente existen para que las personas puedan ejercer sus derechos de manera efectiva» (Corte IDH, 2015b).

La Corte IDH puntualiza que el «el convivir con el VIH no es per se una situación de discapacidad. Sin embargo, en algunas circunstancias, las barreras actitudinales que enfrente una persona por convivir con el VIH generan que las circunstancias de su entorno le coloquen en una situación de discapacidad", bajo la conceptualización que a este respecto establece la Convención sobre los Derechos de las Personas con Discapacidad. (Corte IDH, 2015b).

En el examen del estereotipo de género planteado en el muy relevante caso González y otras (Campo Algodonero, 2009), la jurisprudencia sostuvo que «no son admisibles las consideraciones basadas en estereotipos por la situación de salud de las personas, es decir, preconcepciones de los atributos, conductas o características poseídas por las personas que conviven con cierta enfermedad o el riesgo que dicha enfermedad pueda tener para otras personas» (Corte IDH, 2015b): y observó que la discriminación que afecta a las mujeres por motivos de género se ve agravada cuando concurre el padecimiento de VIH/SIDA (Corte IDH, 2015b) ${ }^{30}$.

Digamos, finalmente, que la Corte Interamericana ha destacado la importancia del acceso a fármacos antirretrovíricos por parte de quienes presentan VIH (Corte IDH, 2015b) ${ }^{31}$.

\section{PROPIEDAD DE LOS PUEBLOS INDÍGENAS Y TRIBALES}

En los términos del art. 11 del Protocolo de San Salvador, la protección del medio ambiente es un derecho que guarda relación con el respeto a la vida digna reconocido por el art. 4 de la Convención Americana. En el periodo objeto de análisis, la Corte IDH determinó que es compatible «la protección de las áreas protegidas con el adecuado uso y goce de los territorios tradicionales de los pueblos indígenas», y que el derecho de estos "y las normas internacionales de medio ambiente deben comprenderse como derechos complementarios y no excluyentes» (Corte IDH, 2015c).

30 Algunas mujeres «padecen discriminación a lo largo de su vida con base en más de un factor combinado con su sexo, lo que aumenta su riesgo de sufrir actos de violencia y otras violaciones de sus derechos humanos. [...]. En el caso de las mujeres con VIH/ SIDA la perspectiva de género exige entender la convivencia con la enfermedad en el marco de los roles y las expectativas que afectan a la vida de las personas, sus opciones e interacciones (sobre todo en relación a su sexualidad, deseos y comportamientos)».

31 Una respuesta limitada al acceso a fármacos antirretrovíricos y otros medicamentos no cumple con las obligaciones de prevención, tratamiento, atención y apoyo derivadas del derecho al más alto nivel posible de salud». 
Se ha planteado nuevamente la conexión entre el territorio y los recursos naturales aprovechados tradicionalmente por los pueblos indígenas y tribales. El uso y goce de esos bienes quedan bajo la protección del art. 21 de la $\mathrm{CADH}$. Con ello se garantiza el modo de vida tradicional y la identidad cultural de dichos pueblos (Corte IDH, 2015d) ${ }^{32}$.

\section{LIBERTAD DE EXPRESIÓN}

El Tribunal Interamericano ha examinado, de tiempo atrás, el contenido de este derecho, básico para el sustento y el desarrollo de una sociedad democrática. Últimamente ha vuelto sobre el tema, gobernado por el art. 13 $\mathrm{CADH}$.

El ejercicio de la libertad de expresión, como de otros derechos humanos, queda a cargo de los individuos. Empero, las condiciones de la vida moderna abren ampliamente la posibilidad de que ese derecho se ejerza a través de personas jurídicas. De ahí la posibilidad de que la persona humana acuda a la jurisdicción interamericana para reclamar derechos que ejerce a través de una persona colectiva (Corte IDH, 2015e) ${ }^{33}$.

En el caso específico de medios de radiodifusión, el Tribunal sostuvo que el art. 13.3 CADH abarca un supuesto de restricción indirecta de aquella libertad, esto es, el «abuso de controles oficiales o particulares [...] de frecuencias radioeléctricas». El Tribunal reconoce la potestad y necesidad que tienen los Estados para regular la actividad de radiodifusión». Esto comprende tanto la definición acerca de «la forma en que se realizan las concesiones, renovacio-

32 En este caso hubo violación del derecho a la propiedad colectiva de la comunidad involucrada, con afectación de la forma de vida, subsistencia, cultura, usos y costumbres e incluso la perdida de la vida de uno de sus miembros. Se emitió condena por violación de los derechos a la propiedad colectiva, la protección judicial, garantías judiciales. Caso Comunidad Garifuna de Punta Piedra y sus Miembros, párr. 167.

La Corte IDH consideró «que las restricciones a la libertad de expresión frecuentemente se materializan a través de acciones estatales o de particulares que afectan, no solo a la persona jurídica que constituye un medio de comunicación, sino también a la pluralidad de personas naturales, tales como sus accionistas o los periodistas que allí trabajan, que realizan actos de comunicación a través de la misma y cuyos derechos también pueden verse vulnerados». Para determinar «si una acción estatal que afectó al medio como persona jurídica también tuvo, por conexidad, un impacto negativo, cierto y sustancial sobre la libertad de expresión de las personas naturales, se debe analizar el papel que cumplen las presuntas víctimas dentro del respectivo medio de comunicación y, en particular, la forma en que contribuían con la misión comunicacional del canal». Caso Granier y otros (Radio Caracas Televisión), párr. 151. 
nes o revocaciones de las licencias», como la planificación e implementación de políticas públicas sobre dicha actividad, siempre con respeto a «las pautas que impone el derecho a la libertad de expresión». En este punto se menciona que «la adopción o renovación de una concesión en materia de radiodifusión no puede ser equiparable a la de otros servicios públicos, por cuanto los alcances del derecho a la libertad de expresión deben permear la regulación sobre la materia» (Corte IDH, 2015e).

El espacio radioeléctrico es un bien escaso. Es necesario asegurar que los medios de comunicación que lo utilizan respondan a la diversidad de visiones o posturas informativas o de opinión que existen en la sociedad (Corte IDH, 2015 e $)^{34}$. En relación con esta orientación democrático en el empleo de los medios, la Corte IDH estableció estándares que deben cumplirse en el «otorgamiento o renovación de concesiones o licencias relacionadas con la actividad de radiodifusión, mediante criterios objetivos que eviten la arbitrariedad» (Corte IDH, 2015e).

\section{GARANTÍAS JUDICIALES}

El Tribunal ha emitido una vasta jurisprudencia sobre múltiples aspectos de las denominadas garantías judiciales, que esencialmente corresponden al debido proceso, regulado principalmente - aunque no exclusivamente- por el art. $8 \mathrm{CADH}$. En el período del que damos noticia se afirmaron los aspectos esenciales de dicha jurisprudencia, y fueron abordadas varias cuestiones específicas que en este artículo figuran en rubros particulares, como son los referentes a presunción de inocencia, mujeres, niños y niñas migrantes, prisión preventiva y otros, a los que nos remitimos.

En el cruce entre las garantías del procedimiento y el derecho a la libertad personal se hallan las medidas cautelares, cuya previsión y aplicación genera condiciones de riesgo o daño para los derechos humanos. Son bien conocidos los motivos que permiten retener dichas medidas, pese a la presunción de inocencia que favorece a los imputados, en tanto se dicta, de ser el caso, sentencia de condena. Ahora bien, la tensión o colisión entre derechos humanos y medidas cautelares obliga a que el régimen de previsión general y particular de éstas y su imposición en casos específicos se ajuste cui-

$34 \mathrm{El}$ "pluralismo de ideas en los medios no se puede medir a partir de la cantidad de medios de comunicación, sino de que las ideas y la información transmitidas sean efectivamente diversas y estén abordadas desde posturas divergentes sin que exista una única visión o postura. Lo anterior debe tenerse en cuenta en los procesos de otorgamiento, renovación de concesiones o licencias de radiodifusión». 
dadosamente a la idea de derecho penal mínimo. La Corte Interamericana ha marchado por este cami Reconoce que en este espacio de consideraciones viene a cuentas el principio de presunción de inocencia - constantemente acogido por los instrumentos del derecho internacional de los derechos humanos-. Implica, ha dicho la Corte, «que nadie sea condenado salvo la existencia de prueba plena o más allá de toda duda razonable de su culpabilidad» (Corte IDH, 2013g) $)^{35}$.

Una medida cautelar especialmente compleja es la prisión preventiva. Esta privación de libertad previa a la condena, invariablemente cuestionada desde la perspectiva de los derechos humanos, debe ser una medida excepcional. No debiera constituir la regla en el ejercicio de la persecución penal por parte del Estado. En este sentido corre la afirmación reiterada del Tribunal: «Se podrá ordenar la prisión preventiva de un procesado solo de manera excepcional y cuando, por ejemplo, no existan otras garantías que aseguren su comparecencia en el juicio» (Corte IDH, 2013g).

En la misma línea, la jurisprudencia interamericana ha afirmado: la aplicación de medidas privativas de libertad en forma consecuente con la $\mathrm{CADH}$ «debe conllevar un carácter excepcional y respetar el principio de presunción de inocencia y los principios de legalidad, necesidad y proporcionalidad, indispensables en una sociedad democrática» (Corte IDH, 2014h) y «la presunción de inocencia exige que las autoridades estatales sean discretas y prudentes al realizar declaraciones públicas sobre un proceso penal» (Corte IDH, $2013 \mathrm{~g})^{36}$.

La responsabilidad internacional del Estado puede verse comprometida "por la respuesta brindada a través de los órganos judiciales respecto a las actuaciones u omisiones imputables a la defensa pública. Si es evidente que la defensa pública actuó sin la diligencia debida, recae sobre las autoridades judiciales un deber de tutela o control» (Corte IDH, 2015f).

La reparación en hipótesis de tortura, implica el deber del Estado de investigar de oficio las violaciones cometidas (Corte IDH, 2013h).

35 Hubo detención ilegal y arbitraria de una persona, tortura y tratos crueles, inhumanos y degradantes, así como violación sexual; igualmente, infracciones al debido proceso. El Tribunal condenó por violación del derecho a la libertad personal, a las garantías judiciales de competencia, independencia e imparcialidad de las autoridades judiciales, y a la integridad personal en relación con la Convención sobre la Tortura.

36 «La presunción de inocencia no impide que las autoridades mantengan debidamente informada a la sociedad sobre investigaciones penales, pero requiere que cuando lo hagan, guarden la debida discreción y circunspección necesaria para garantizar la presunción de inocencia de los posibles involucrados». 


\section{DERECHOS POLÍTICOS}

El art. 23 de la Convención Americana no solo protege el derecho político a ser elegido, sino también el de «tener una oportunidad real de ejercer el cargo para el cual el funcionario ha sido electo». El derecho a una participación política efectiva implica que el ciudadano tenga tanto el derecho como la posibilidad de participar en la dirección de los asuntos públicos (Corte IDH, 2014i).

Por lo que toca al ámbito de los derechos políticos, es preciso que «el Estado genere las condiciones y mecanismos óptimos» para estos «puedan ser ejercidos de forma efectiva». La condición de igualdad en esta materia se refiere al acceso a la función mediante elección popular o a través de nombramiento o designación (Corte IDH, 2014i).

\section{EXPULSIÓN COLECTIVA DE MIGRANTES}

La Corte rechaza la expulsión colectiva, indiscriminada, de personas migrantes. Esa medida se debe aplicar, en su caso, de manera individual, atendiendo a las circunstancias concretas de cada caso y examinando la situación migratoria del sujeto (Corte IDH, 2014b). La jurisprudencia estatuye las garantías que es preciso observar en cualquier procedimiento de expulsión de personas (Corte IDH, 2014b) ${ }^{37}$.

\section{REFUGIADOS}

Entre los ejes principales del régimen aplicable a la figura del refugio, que posee suma relevancia en el orden internacional, figura el principio de no devolución de refugiados, asilados y solicitantes de ese beneficio. La Corte IDH ha determinado que la protección contra la devolución opera con independencia del estatuto legal o la condición migratoria en el Estado de que se

37 Entre estas garantías figuran: «a) ser informada expresa y formalmente de los cargos en su contra y de los motivos de la expulsión o deportación. Esta notificación debe incluir información sobre sus derechos, tales como: i) la posibilidad de exponer sus razones y oponerse a los cargos en su contra, y ii) la posibilidad de solicitar y recibir asistencia consular, asesoría legal y, de ser el caso, traducción o interpretación; b) en caso de decisión desfavorable, debe tener derecho a someter su caso a revisión ante la autoridad competente y presentarse ante ella para tal fin, y c) ser formal y fehacientemente notificada de la eventual decisión de expulsión, que debe estar debidamente motivada conforme a la ley». Caso de personas dominicanas y haitianas expulsadas. 
trate, y constituye «un componente integral de la protección internacional de los refugiados» (Corte IDH, 2013i).

En consecuencia, las personas que pretenden adquirir la condición de refugiados, «no pueden ser rechazadas en la frontera o expulsadas sin un análisis adecuado e individualizado de sus peticiones». Por ello, los Estados «deben asegurarse (de) que la persona que solicita asilo se encuentra en la capacidad de acceder a una protección internacional apropiada mediante procedimientos justos y eficientes de asilo en el país a donde se le estaría expulsando». Con respecto al non refoulement, los Estados deben abstenerse de devolver o expulsar a una persona que solicita asilo donde exista la posibilidad de que sufra algún riesgo de persecución o bien a (un Estado) desde donde (los sujetos) puedan ser retornados al país donde sufren dicho riesgo (la llamada «devolución indirecta») (Corte IDH, 2013i).

\section{EXTRADICIÓN, DEVOLUCIÓN Y PENA DE MUERTE}

El caso Wong Ho Wing, que atrajo la atención general, constituyó «la primera oportunidad» en la que la Corte Interamericana se pronunció «sobre las obligaciones de los Estados Parte de la Convención en el marco de procesos de extradición». Advirtió que tanto la obligación de garantizar los derechos a la vida y a la integridad personal, como el principio de no devolución cuando existe riesgo de tortura o de otras formas de trato cruel, inhumano o degradante, bien riesgo para la vida del sujeto extraído, «se aplica a todas las modalidades de devolución de una persona a otro Estado, incluso por extradición» (Corte IDH, 2015g).

Los Estados que "han abolido la pena de muerte no pueden exponer a una persona bajo su jurisdicción al riesgo real y previsible» de aplicación de la pena capital. Por lo tanto, no es admisible la expulsión, «por deportación o extradición, (de) las personas bajo su jurisdicción si se puede prever razonablemente que pueden ser condenadas a muerte, sin exigir garantías de que dicha pena no les será aplicada» (Corte IDH, 2015g).

\section{CIRCULACIÓN, RESIDENCIA Y DESPLAZAMIENTO}

El derecho de circulación y de residencia «puede ser vulnerado de manera formal o por restricciones de facto si el Estado no ha establecido las condiciones ni provisto los medios que permiten ejercerlo». La jurisprudencia proporciona ejemplos de esta situación, y al respecto menciona: se vulnera el derecho "cuando una persona es víctima de amenazas u hostigamientos y el Estado no provee las garantías necesarias para que pueda transitar y residir libremente en el territorio de que se trate, incluso cuando las amenazas y hosti- 
gamientos provienen de actores no estatales». La falta de investigación efectiva sobre estos hechos puede propiciar o perpetuar un exilio o desplazamiento forzado (Corte IDH, 2014i) ${ }^{38}$.

A través de la interpretación evolutiva del art. 22.1 de la Convención y de acuerdo con las normas de interpretación contenidas en el art. 29.b del mismo instrumento, la Corte estima que aquella norma protege el derecho del individuo «a no ser desplazado forzadamente dentro de un Estado Parte» en la CADH (Corte IDH, 2013e). La jurisprudencia expuso las obligaciones estatales en hipótesis de desplazamiento forzado, que abarcan, entre otros extremos, el favorecimiento del retorno y la reasunción de derechos del desplazado (Corte IDH, 2013e) $)^{39}$.

\section{USO DE LA FUERZA}

Cuando resulte indispensable el empleo de la fuerza, esta debe aplicarse con arreglo a los principios de finalidad legítima, absoluta necesidad y proporcionalidad; además «es imperante que, con el objetivo de evitar confusión e inseguridad, los funcionarios encargados de hacer cumplir la ley se identifiquen como tales y den una clara advertencia de su intención de emplear armas de fuego en todo momento; sobre todo cuando se encuentran realizando operativos y, en especial, en situaciones que por su naturaleza pongan en peligro los derechos fundamentales de las personas» (Corte IDH, 2014j). La Corte reiteró el parámetro a seguir para el empleo de la fuerza (Corte IDH, 2014j) ${ }^{40}$.

38 Hubo irregularidades en la investigación y falta de diligencia por parte del Estado, tratándose del asesinato de un defensor de derechos humanos; inobservancia del plazo razonable y carencia de protección a las personas que intervienen en el proceso. El Estado violó el derecho a la integridad personal, el derecho a la circulación y residencia, además de los derechos políticos, a las garantías judiciales y a la protección judicial.

39 «La obligación de los Estados en relación con los desplazados abarca «no sólo el deber de adoptar medidas de prevención sino también proveer las condiciones necesarias para un retorno digno y seguro a su lugar de residencia habitual o su reasentamiento voluntario en otra parte del país. Para ello, se debe garantizar su participación plena en la planificación y gestión de su regreso o reintegración».

40 Para determinar la proporcionalidad del uso de la fuerza, debe evaluarse la gravedad de la situación que enfrenta el funcionario. Para ello, se debe considerar, entre otras circunstancias: la intensidad y peligrosidad de la amenaza; la forma de proceder del individuo; las condiciones del entorno, y los medios de los que disponga el funcionario para abordar una situación específica. Además, este principio exige que el funcionario encargado de hacer cumplir la ley busque en toda circunstancia reducir al mínimo los 


\section{DERECHO DE LOS DERECHOS HUMANOS Y DERECHO INTERNACIONAL HUMANITARIO}

La Corte IDH destacó una vez más la vinculación entre el derecho internacional de los derechos humanos y el derecho internacional humanitario (Corte IDH, 2015h). Se refirió a la obligación a cargo del Estado de aplicar el principio de distinción entre civiles y combatientes (Corte IDH, 2015h) ${ }^{41}$.

\section{BIBLIOGRAFÍA}

Astudillo, C. (2014). El bloque y el parámetro de constitucionalidad en México. México: Tirant lo Blanch.

Brewer-Carías, A. R. y Santofimio, J. O. (2013). Control de convencionalidad y responsabilidad del Estado. Bogotá: Universidad Externado de Colombia.

Caballero Ochoa, J. L. (2013). La interpretación conforme. El modelo constitucional ante los tratados internacionales sobre derechos humanos y el control de convencionalidad. México: Porrúa.

De Vergottini, G. (2010). Más allá del diálogo entre tribunales, comparación y relación entre jurisdicciones. Pamplona: Civitas-Thomson Reuters.

Ferrer Mac-Gregor Poisot, E. (coord.) (2012a). El control difuso de convencionalidad. Diálogo entre la Corte Interamericana de Derechos Humanos y los jueces nacionales. México: FUNDAP.

- (2012b). Interpretación conforme y control difuso de convencionalidad. El nuevo paradigma para el juez mexica. En E. Ferrer Mac-Gregor Poisot (coord.). El control difuso de convencionalidad. Diálogo entre la Corte Interamericana de Derechos Humanos y los jueces nacionales. México: FUNDAP.

daños y lesiones que pudieran causarse a cualquier persona, así como utilizar el nivel de fuerza más bajo necesario para alcanzar el objetivo legal buscado».

41 «El principio de distinción se refiere a una norma consuetudinaria aplicable a los conflictos armados internacionales y no internacionales, en la cual se establece que '[l] as partes en conflicto deberán distinguir en todo momento entre personas civiles y combatientes', de modo tal que '[l] os ataques sólo podrán dirigirse contra combatientes' y '[l]os civiles no deben ser atacados'. Asimismo, el derecho internacional humanitario contiene reglas específicas que determinan quiénes califican como personas acreedoras de las salvaguardas fundamentales del art. 3 común a los cuatro Convenios de Ginebra; abarca a las personas que no participen directamente en las hostilidades, incluidos los miembros de las fuerzas armadas que hayan depuesto las armas y las personas puestas fuera de combate por enfermedad, herida, detención o por cualquier otra causa'». 
García Ramírez, S. (2014). La tutela de los derechos humanos en la jurisdicción interamericana. Aportaciones, recepción y diálogo. México: Porrúa, IMDPC.

- (2015). La Corte Interamericana de Derechos Humanos. México: UNAM, Instituto de Investigaciones Jurídicas, Porrúa.

- y Del Toro Huerta, M. (2015). México ante la Corte Interamericana de Derechos Humanos. Decisiones, trasformaciones y nuevos desafios. México: UNAM, Instituto de Investigaciones Jurídicas/Ed. Porrúa.

- y Morales Sánchez, J. (2009). Afirmaciones y novedades en la jurisprudencia de la Corte Interamericana de Derechos Humanos (2009-2012). Anuario Iberoamericano de Justicia Constitucional, 13, 498-539. Disponible en: http://www.cepc.gob.es/ publicaciones/revistas/revistaselectronicas?IDR=8\&IDN=681\&IDA=27566.

- (2015). La reforma constitucional sobre derechos humanos (2009-2011). México: UNAM, Instituto de Investigaciones Jurídicas, Porrúa.

García Villegas Sánchez Cordero, P. M. (coord.) (2013). El control de convencionalidady las cortes nacionales. La perspectiva de los jueces mexicanos. México: Porrúa.

González Morales, F. (2013). Sistema Interamericano de Derechos Humanos. Valencia: Tirant lo Blanch.

Gozaíni, O. A. (2016). Procedimientos en la Comisión y ante la Corte Interamericana de Derechos Humanos. Bogotá: Nueva Jurídica.

Hitters, J. C. (2009). Control de constitucionalidad y control de convencionalidad. Comparación. Buenos Aires: La Ley.

Langford, M. (ed.) (2013). Teoría y jurisprudencia de los derechos sociales. Tendencias emergentes en el Derecho internacional y comparado. Bogotá: Siglo del Hombre Editores, Universidad de los Andes.

Peláez Ferrusca, M. (coord.) (2014). Criterios y jurisprudencia interamericana de derechos humanos: influencia y repercusión en la justicia penal. México: UNAM, Instituto de Investigaciones Jurídicas/Instituto de Formación de Personal.

Rey Cantor, E. (2008). Control de convencionalidad de las leyes y derechos humanos. México: Porrúa.

Saavedra, P. (coord.) (2013). Impacto de las sentencias de la Corte Interamericana de Derechos Humanos. México: Tirant Lo Blanch.

Sagüés, N. P. (2013). La interpretación judicial de la Constitución. De la constitución nacional a la constitución convencionalizada. México: Porrúa.

Sandoval Terán, A. (coord.) (2014). ¿Hay justicia para los derechos económicos, sociales y culturales? México: Suprema Corte de Justicia de la Nación/UNAM, Instituto de Investigaciones Jurídicas.

Santolaya Machetti, P. et al. (coords.) (2015). El diálogo entre los Sistemas Europeo y Americano de Derechos Humanos. Lima, Perú: ECB Ediciones.

Von Bogdandy, A. et al. (coords.) (2010). La justicia constitucional y su internacionalización. ¿Hacia un ius constitucionale commune en América Latina? México: Instituto de Investigaciones Jurídicas, UNAM, Instituto Max Planck, Instituto Iberoamericano de Derecho Constitucional. 


\section{JURISPRUDENCIA}

Convención Interamericana contra el Racismo y la Discriminación Racial (A-69), firmado en Antigua, Guatemala [Convención] (6 de junio de 2013).

Convención Interamericana contra toda Forma de Discriminación e Intolerancia (A-68) [Convención] (5 de junio de 2013). Disponible en: http://www.oas.org/dil/esp/ tratados_B-32_Convencion_Americana_sobre_Derechos_Humanos.htm.

Convención Interamericana sobre Protección de los Derechos Humanos de las Personas Mayores (A-70) [Convención] (15 de junio de 2015). Disponible en: http://www. oas.org/es/sla/ddi/tratados_multilaterales_interamericanos_A-70_derechos_humanos_personas_mayores.asp.

Corte IDH. Disponible en: www.Corte IDH.or.cr/.

Corte IDH. Informes temáticos (Corte IDH. Informes temáticos) Disponible en: http:// www.oas.org/es/cidh/informes/tematicos.asp.

Corte IDH. Informes de Pais. (Corte IDH, Informe de País). Disponible en: http://www. oas.org/es/cidh/informes/pais.asp.

Corte IDH (2006). Casos Penal Miguel Castro y Castro. Sentencia de 25 de noviembre de 2006, Serie C 160 Serie y C 181, párrs. 311 y 312. Disponible en: http://www. Corte IDH.or.cr/docs/casos/articulos/seriec_181_esp.pdf.

Corte IDH (2010). Caso Fernández Ortega y otras. Sentencia de 30 de agosto de 2010, Serie C 215 y 224, párr. 128. Disponible en: http://www.Corte IDH.or.cr/docs/ casos/articulos/resumen_215_esp.pdf.

Corte IDH (2012). Caso Costa y Pavan .TEDH, Sentencia de 28 de agosto de 2012. Disponible en: http://www.Corte IDH.or.cr/docs/casos/articulos/seriec_257_esp.pdf.

Corte IDH (2013). Caso Osorio Rivera y Familiares. Excepciones Preliminares, Fondo, Reparaciones y Costas. 26 de noviembre de 2013, párr.21. Disponible en: http:// www.Corte IDH.or.cr/docs/casos/articulos/seriec_257_esp.pdf.

Corte IDH (2013a). Caso Luna López. Fondo, Reparaciones y Costas. Sentencia de 10 de octubre de 2013. Serie C 269, párr. 119. Disponible en: http://www.Corte IDH. or.cr/docs/casos/articulos/seriec_269_esp.pdf.

Corte IDH (2013b). Caso Gutiérrez y Familia. Fondo, Reparaciones y Costas. Sentencia de 25 de noviembre de 2013. Serie C 271, párr. 78. Disponible en: http://www. Corte IDH.or.cr/docs/casos/articulos/seriec_271_esp.pdf.

Corte IDH (2013c). Caso Mémoli. Excepciones Preliminares, Fondo, Reparaciones y Costas. 22 de agosto de 2013. Serie C 265, párr. 125. Disponible en: http://www. Corte IDH.or.cr/cf/Jurisprudencia2/busqueda_casos_contenciosos.cfm?lang=es.

Corte IDH (2013d). Caso Mendoza y otros. Excepciones Preliminares, Fondo y Reparaciones. 14 de mayo de 2013, Serie C 260, párr. 141, 142, 143, 145, 146, 147, 151, 162, 166. Disponible en: http://www.Corte IDH.or.cr/docs/casos/articulos/ seriec_260_esp.pdf.

Corte IDH (2013e). Caso de las Comunidades Afrodescendientes Desplazadas de la Cuenca del Río Cacarica (Operación Génesis). Excepciones Preliminares, Fondo, Reparaciones y Costas. 20 de noviembre de 2013, Serie C 270, párr. 185, 186, 
219, 220, 315, 329, 327. Disponible en: http://www.Corte IDH.or.cr/docs/casos/ articulos/seriec_270_esp.pdf.

Corte IDH (2013f). Caso Suárez Peralta. Excepciones Preliminares, Fondo, Reparaciones y Costas. 21 de mayo de 2013, Serie C 261, párr. 131. Disponible en: http://www. Corte IDH.or.cr/docs/casos/articulos/seriec_261_esp.pdf.

Corte IDH (2013g). Convención sobre la Tortura. Caso J. Excepción Preliminar, Fondo, Reparaciones y Costas. Sentencia de 27 de noviembre de 2013. Serie C 275, párr. 157, 228, 244, 247. Disponible en: http://www.Corte IDH.or.cr/docs/casos/articulos/seriec_275_esp.pdf.

Corte IDH (2013h). Caso García Lucero y otras. Excepción Preliminar, Fondo y Reparaciones. Sentencia de 28 de agosto de 2013. Serie C 267, párr. 183. Disponible en: http://www.Corte IDH.or.cr/docs/casos/articulos/seriec_267_esp.pdf.

Corte IDH (2013i). Caso Familia Pacheco Tineo. Excepciones Preliminares, Fondo, Reparaciones y Costas. Sentencia de 25 de noviembre de 2013. Serie C 27, párr. 152 y 153. Disponible en: http://www.Corte IDH.or.cr/docs/casos/articulos/resumen_272_esp.pdf.

Corte IDH (2014). Opinión Consultiva OC-21/14, «Derechos y garantías de niñas y niños en el contexto de la migración y/o en necesidad de protección internacional», 19 de agosto de 2014, párrs. 110-114, 150, 280, 123-149. Disponible en: http:// www.Corte IDH.or.cr/docs/opiniones/resumen_seriea_21_esp.pdf.

Corte IDH (2014a). Caso Liakat Ali Alibux. Excepciones Preliminares, Fondo, Reparaciones y Costas, 30 de enero de 2014. Disponible en: http://www.Corte IDH.or.cr/ docs/casos/articulos/seriec_276_esp.pdf.

Corte IDH (2014b). Caso de personas dominicanas y haitianas expulsadas. 28 de agosto de 2014. .Serie C 282, párr. 311, .357, 359, 360, 381 y 356. Disponible en: http:// Corte IDH.or.cr/docs/casos/articulos/seriec_282_esp.pdf.

Corte IDH (2014c). Caso de Allan Brewer Carías..Excepciones Preliminares, Sentencia de 26 de mayo de 2014, Serie C 278. Disponible en: http://www.Corte IDH.or.cr/ docs/casos/articulos/seriec_278_esp.pdf.

Corte IDH (2014d). Caso Rochac Hernández y otros. Fondo, Reparaciones y Costas. Sentencia. 14 de octubre de 2014, Serie C 285, párr. 116, 107 y 113. Disponible en: http://www.Corte IDH.or.cr/docs/casos/articulos/seriec_285_esp.pdf.

Corte IDH (2014e). Caso Rodríguez Vera y otros. (Desaparecidos del Palacio de Justicia). Excepciones Preliminares, Fondo, Reparaciones y Costas. 14 de noviembre de 2014. Serie C 287, párr. 425. Disponible en: http://www.Corte IDH.or.cr/docs/ casos/articulos/seriec_287_esp.pdf.

Corte IDH (2014f). Caso Veliz Franco y otros. Excepciones Preliminares, Fondo, Reparaciones y Costas. 19 de mayo de 2014. Serie C 277, párr. 209 y 136. Disponible en: http://www.Corte IDH.or.cr/docs/casos/articulos/seriec_277_esp.pdf.

Corte IDH (2014f). Caso Espinoza Gonzáles. Excepciones Preliminares, Fondo, Reparaciones y Costas. 20 de noviembre de 2014. Serie C 289, párr. 150, 226, 193. Disponible en: http://www.Corte IDH.or.cr/docs/casos/articulos/seriec_289_esp.pdf.

Corte IDH (2014g). Caso Norín Catrimán y otros (Dirigentes, miembros y activista del Pueblo Indígena Mapuche). Fondo, Reparaciones y Costas. Sentencia de 29 
de mayo de 2014. Serie C 279, párr. 310. Disponible en: http://www.Corte IDH. or.cr/docs/casos/articulos/seriec_279_esp.pdf.

Corte IDH (2014i). Caso Defensor de Derechos Humanos y otros. Excepciones Preliminares, Fondo, Reparaciones y Costas. Sentencia de 28 de agosto de 2014. párr. 166, 185 y 186. Disponible en: http://www.Corte IDH.or.cr/docs/casos/articulos/ seriec_283_esp.pdf.

Corte IDH (2014j). Caso Hermanos Landaeta Mejías y otros. Excepciones Preliminares, Fondo, Reparaciones y Costas. Sentencia de 27 de agosto de 2014. Serie C 281, párr. 135 y 136. Disponible en: http://Corte IDH.or.cr/docs/casos/articulos/ seriec_281_esp.pdf.

Corte IDH (2015). Informe 2015. Disponible en: http://www.Corte IDH.or.cr/tablas/ informe2015.

Corte IDH (2015a). Caso Velásquez Paiz y otros. Excepciones Preliminares, Fondo, Reparaciones y Costas. (2015, 19 de noviembre). Serie C 307, párr. 108, 122, 144, 148, 176,197 y 2007. Disponible en: http://www.Corte IDH.or.cr/docs/casos/articulos/seriec_307_esp.pdf.

Corte IDH (2015b). Caso Gonzales Lluy y otros. Excepciones Preliminares, Fondo, Reparaciones y Costas. Sentencia de 01 de septiembre de 2015. Serie C 298, párr. 169, 171, 184,190, 193, 255 y 236. Disponible en: http://www.Corte IDH.or.cr/docs/ casos/articulos/seriec_298_esp.pdf.

Corte IDH (2015c). Caso Pueblos Kaliña y Loko Fondo, Reparaciones y Costas. Sentencia de 25 de noviembre de 2015. Serie C 309, párr. 173. Disponible en: http:// www.Corte IDH.or.cr/docs/casos/articulos/seriec_309_esp.pdf.

Corte IDH (2015d). Caso Comunidad Garífuna de Punta Piedra y sus Miembros. Excepciones preliminares, Fondo, Reparaciones y Costas, Sentencia de 8 de octubre de 2015, párr. 167. Disponible en: http://www.Corte IDH.or.cr/docs/casos/articulos/seriec_304_esp.pdf.

Corte IDH (2015e). Caso Granier y otros (Radio Caracas Televisión). Excepciones Preliminares, Fondo, Reparaciones y Costas, Sentencia de 22 de junio de 2015, Serie C 293, párr. 151, 165, 170 y 171. Disponible en: http://www.Corte IDH.or.cr/docs/ casos/articulos/seriec_293_esp.pdf.

Corte IDH (2015f). Caso Ruano Torres y otros. Fondo, Reparaciones y Costas. Sentencia de 5 de octubre de 2015. Serie C 303, párr. 168. Disponible en: http://www. Corte IDH.or.cr/docs/casos/articulos/seriec_303_esp.pdf.

Corte IDH (2015g). Caso Wong Ho Wing. Excepción Preliminar, Fondo, Reparaciones y Costas. Sentencia de 30 de junio de 2015. Serie C 297, párr. 130 y 134. Disponible en: http://www.Corte IDH.or.cr/docs/casos/articulos/seriec_297_esp.pdf.

Corte IDH (2015h). Caso Cruz Sánchez y otros, Excepciones Preliminares, Fondo, Reparaciones y Costas, Sentencia de 17 de abril de 2015, Serie C 292, párr. 272 y 276. Disponible en: http://www.Corte IDH.or.cr/docs/casos/articulos/resumen_292_ esp.pdf.

Corte IDH (2016). Caso Duque. Excepciones Preliminares, Fondo, Reparaciones y Costas. Sentencia de 26 de febrero de 2016. Serie C 310, párrs. 104-106, 121-124. Disponible en: http://www.Corte IDH.or.cr/docs/casos/articulos/seriec_310_esp.pdf. 